\title{
Hardening Characteristics of Self-healing Cement Mortars
}

\author{
Tong $\mathrm{Ye}^{1,2^{*}}$, Zhuangzhaug $\mathrm{Liu}^{1,2}$, and $\mathrm{Lin}^{\mathrm{Li}}{ }^{1,2}$ \\ ${ }^{1}$ School of Highway, Chang' an University, Xi' an China; \\ ${ }^{2}$ Key Laboratory of Special Area Highway Engineering, MoE, Chang'an University, Xi'an China
}

\begin{abstract}
In water conservancy and transportation engineering, self-healing cement has been widely used. This paper researches the optimal water-cement ratio of self-healing cement mortar to obtain the best basic performance, and on this basis, researches the occasional effect of self-healing agent and fibers on the mechanical properties of cement mortar. In addition, the research on the shrinkage characteristics and impermeability of cement mortar by self-healing agent was carried out to provide the basis for the curing methods of bacterial cement in the project. Finally, the microstructure of self-healing cement provides a theoretical basis for the macroscopic performance. The results show that the best water-cement ratio of the self-healing cement mortar is 0.42 , and the fiber can effectively improve the toughness of the material. In addition, bacterial can increase the auto-shrinkage and impermeability of cement. These results will offer valuable experience for experimenters to assist the experiment work.
\end{abstract}

\section{Introduction}

Cement concrete is the most widely used building materials in the engineering field, and its hardening characteristics and durability have a vital impact on the safety of engineering structures. During the service period of concrete, cracks will occur due to various factors. This oblique crack will affect the durability of concrete materials. Therefore, the research on selfhealing of cement materials is very important, and related research has been extensively carried out ${ }^{[1-2]}$. Self-healing cement has been widely used in many fields. Studies have shown that: self-healing cement can improve the mechanical properties (hardness, strength) and permeability of cement materials ${ }^{[3]}$, and can repair defects in building materials ${ }^{[4]}$.

Bacteria and fiber play an important role in the selfhealing process of cement. Fiber and bacteria play a synergistic effect and accelerate the self-healing process ${ }^{[5]}$. Previous studies have shown that fiber can be used as a matrix for the precipitation of calcium carbonate produced by bacterial reactions, allowing concrete to obtain better self-healing properties ${ }^{[6-8]}$. However, the research on the hardening characteristics of mixed bacterial and mortar itself is still very limited. Therefore, in this study, a variety of indicators were used to study the mechanical properties, shrinkage characteristics and impermeability of microbes and fibers used in cement mortar.

\section{Materials and Methods}

\subsection{Raw materials}

This study employed Ordinary Portland cement (OPC42.5). The bactiria used in this article is a selfhealing agent produced in a factory for self-healing concrete.

\subsection{Specimen preparation}

Cement paste was prepared and prism samples $(40 \times 40 \times 160 \mathrm{~mm})$ according to JTG E30-2005 and then cured under a standard condition $\left(20^{\circ} \mathrm{C}, 95 \%\right.$ relative humidity). After curing for 24 hours, the sample will be demoulded and continue to be cured in a standard condition.

\subsection{Mechanical properties}

Based on JTG E30-2005, the mechanical properties of cement paste were tested. The loading rate of bending strength was $50 \pm 10 \mathrm{~N} / \mathrm{s}$, and the loading rate of compressive strength was $2400 \pm 200 \mathrm{~N} / \mathrm{s}$.

\subsection{Autogenous}

The water-cement ratio is 0.26 , and the lime-sand ratio is $1 / 2$. Cement paste was prepared and prism samples $(25 \times 25 \times 280 \mathrm{~mm})$. After the test piece is formed, the mold and the sample are sealed with a plastic film. After curing at $20^{\circ} \mathrm{C}$ for $24 \mathrm{~h}$, the mold is removed and the test

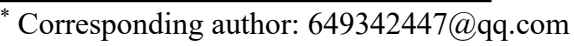


piece is sealed. The length of each test piece is measured every $24 \mathrm{~h}$.

\subsection{Impermeability}

The impermeable pressure test of cement mortar is carried out in accordance with GBJ82-85. The mortar specimen adopts a round table body with a wound diameter of $70 \mathrm{~mm}$, a lower mouth of $80 \mathrm{~mm}$ and a height of $30 \mathrm{~mm}$, and 6 impermeable specimens as a set.

\section{Experimental results}

\subsection{Influence of water-cement ratio}

In order to characterize the influence of water-cement ratio on the mechanical properties after mixing with selfhealing agent, five mixing ratios were selected, which were $0.36,0.38,0.4,0.42$ and 0.44 , and the self-healing agent content was 0 and 2\%. Fig. 1 shows the effect of water-cement ratio on the flexural strength of cement mortar under different self-healing agent content. It can be seen from the Fig. 1 that when the water-cement ratio is less than 0.42 at the age of $3 \mathrm{~d}$ and $7 \mathrm{~d}$, the flexural strength increases with the increase of water-cement ratio. When the water-cement ratio is greater than 0.42 , the flexural strength is reduced. The flexural strength is improved to a certain extent after self-healing agent are incorporated, and after self-healing agent are incorporated, the change trend of flexural strength is the same as that of the control sample. In addition, as the water-cement ratio increases, the increase in the flexural strength of the self-healing mortar by bacteria becomes smaller. In the early age, In the early age, the selfrepairing agent accelerates hydration and effectively improves the flexural strength.

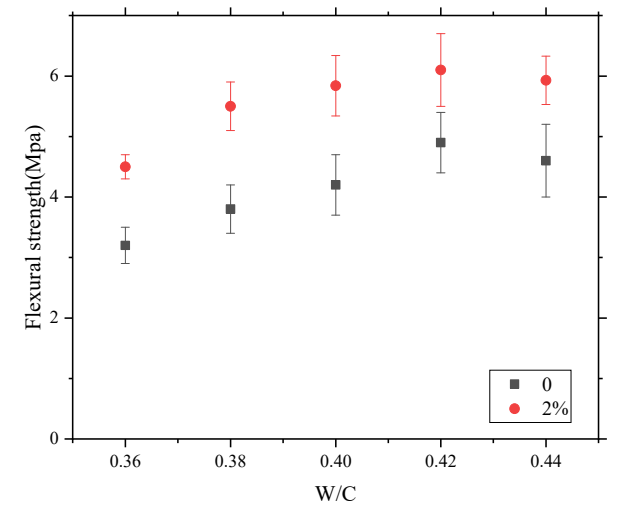

(a)

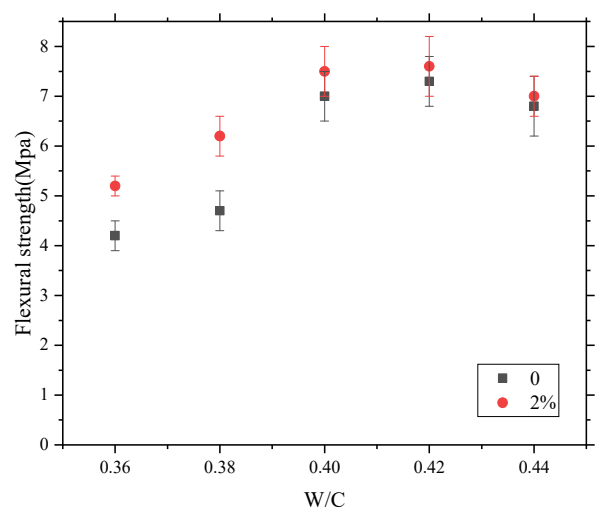

(b)

Fig. 1. Effect of water-cement ratio on flexural strength (a) $3 d$ (b) $7 \mathrm{~d}$

Fig. 2 shows the change trend of the compressive strength of the mixed self-healing agent and the control sample with the water-cement ratio, which is consistent with the change trend of the flexural strength. With the increase of water-cement ratio, the compressive strength first increases and then decreases. The maximum value is reached at 0.42 . And with the increase of watercement ratio, the improvement of self-healing compressive strength is smaller.

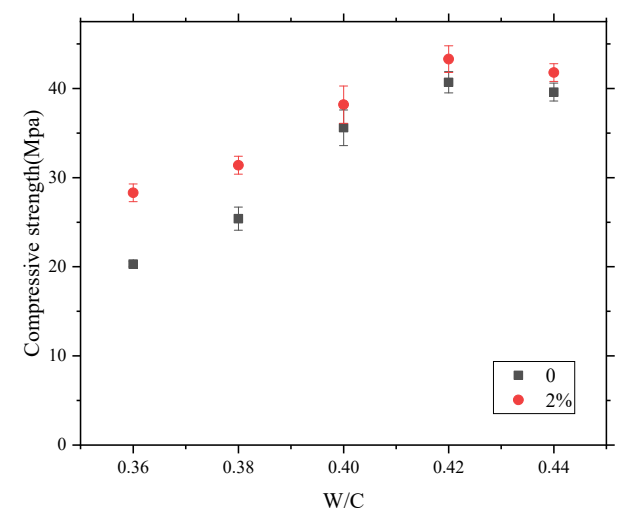

(a)

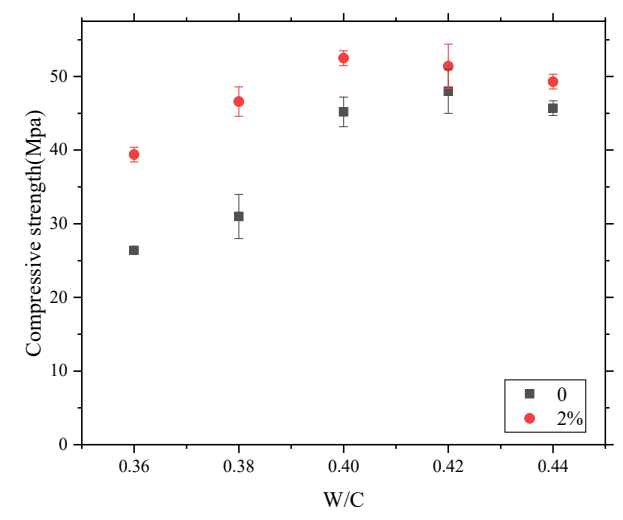

(b)

Fig. 2. Effect of water-cement ratio on compressive strength (a) $3 \mathrm{~d}(\mathrm{~b}) 7 \mathrm{~d}$ 
It can be concluded that the sample with a watercement ratio of 0.42 without water-reducing agent has the best mechanical properties after standard curing. A self-healing agent content of $2 \%$ can effectively improve the mechanical properties of cement mortar. When microbes are incorporated, the water-cement ratio should be set at about 0.42 .

\subsection{The influence of fiber}

Fig. 3 shows the influence of glass fiber content on the flexural strength of cement mortar with self-healing agent content of $2 \%$ and water-cement ratio of 0.42 and 0.45 . After fiber is added, the workability of the mortar is changed due to the addition of solids. Therefore, the water-cement ratio is set to 0.45 at the same time to test the compressive and flexural strength of the fiber mortar. It can be seen that with the increase of fiber content, the flexural strength has not been greatly improved, but when the specimen reaches the flexural strength, the specimen does not break, which can effectively improve the toughness of the material. It can be concluded that the fiber cannot improve the strength of the material, but it can effectively control the width of the material's cracks and provide good conditions for the self-healing of the material.

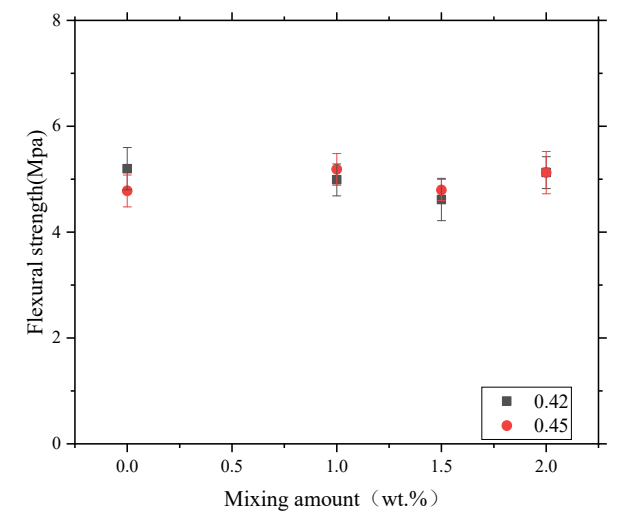

(a)

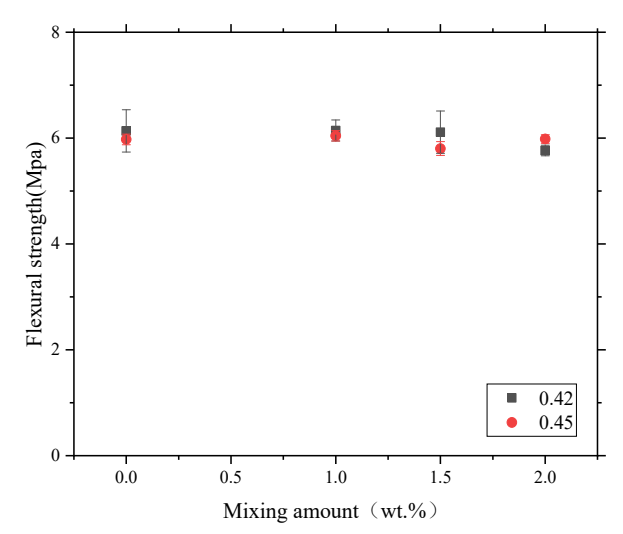

(b)

Fig. 3. Effect of fiber content on flexural strength (a) $3 d$ (b)7d

As shown in Fig. 4, the influence trend of glass fiber content with the compressive strength of self-healing cement mortar. It can be seen from the Fig. 4 that the incorporation of glass fiber will reduce the compressive strength of the mortar. In addition, when the fiber content is low, the lower water-cement ratio has higher strength, and when the fiber content is $2 \%$, it is necessary to increase the water-cement ratio to increase the strength. Therefore, if a larger amount of fiber needs to be blended, the water-cement ratio should be appropriately increased to meet the mechanical properties of the material.

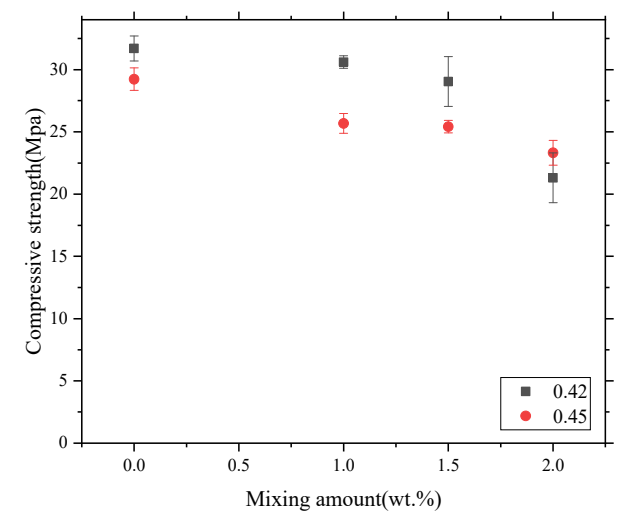

(a)

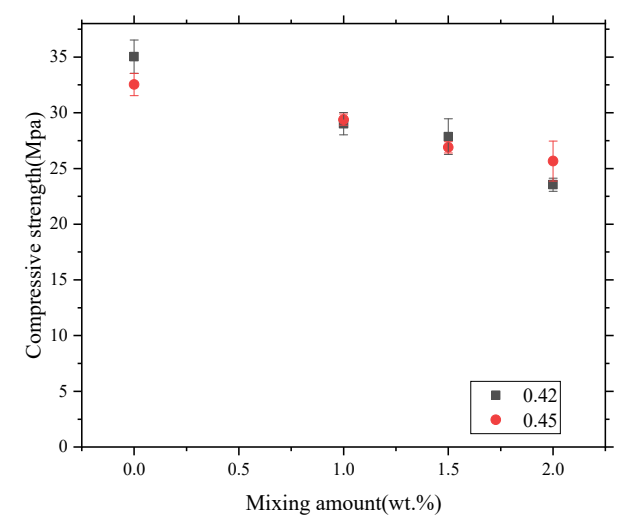

(b)

Fig. 4. Effect of fiber content on compressive strength (a)3d (b) $7 \mathrm{~d}$

\subsection{Shrinkage and impermeability}

Fig. 5 shows the trend of auto-shrinkage of cement mortar with age under different self-healing agent content. The auto-shrinkage of mortar increases with the increase of self-healing agent content. Under any mix ratio, it reaches equilibrium at $2 \mathrm{~d}$ age. At this point, the autogenous contraction increased rapidly before that, and the autogenous contraction increased slowly after 2 days. 


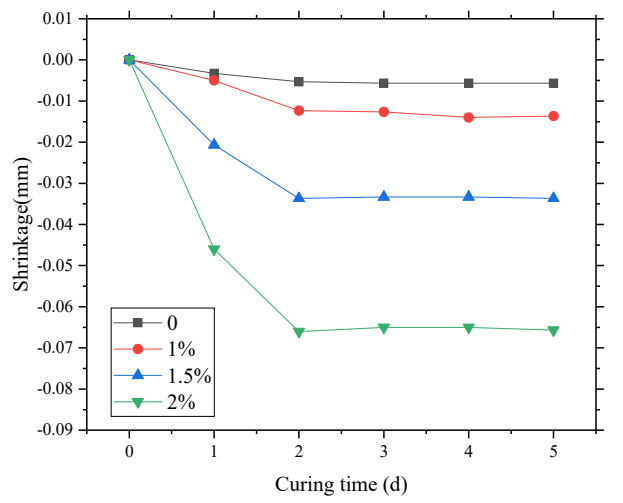

Fig. 5. The effect of self-healing agent content on autogenous shrinkage

Fig. 6 shows the change trend of the impermeability of cement mortar with the amount of self-healing agent. The results show that the impermeability pressure of cement mortar reaches the peak when the amount is $1.5 \%$, and increases with the increase of the amount when the amount is below $1.5 \%$. The $1.5 \%$ impermeability pressure becomes smaller. The main reason is that a small amount of self-healing agent react with cement to fill the micro-pores in the material. When the amount is large, too many self-healing agent reduce the water-cement ratio, which slows down the early hydration reaction, reduces hydration products, and reduces its impermeability pressure to a certain extent. When determining the mix ratio, the amount of selfhealing agent should be appropriately controlled to make the material obtain a strong impermeability.

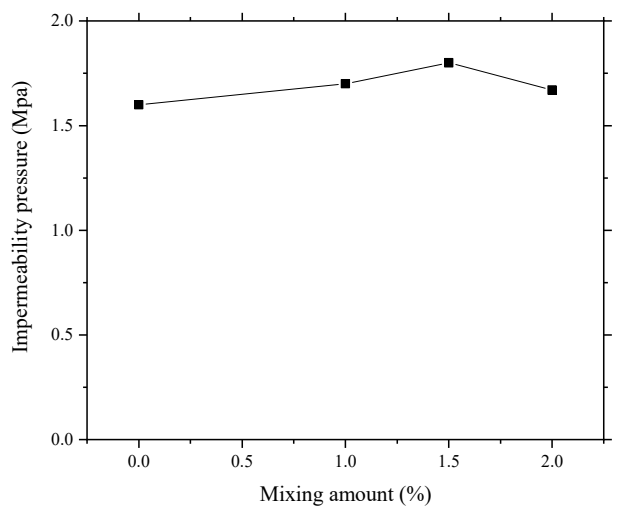

Fig. 6 Effect of self-healing agent content on anti-osmosis

\subsection{Micro morphology}

In order to explain the influence of different self-healing agent dosages on the mechanical properties of cement mortar, electron micrographs of hardened cement mortar were collected, as shown in Fig. 7, which shows the control group and $2 \%$ self-healing agent cement mortar. It can be seen from Fig. 7(a) and Fig. (b) that the porosity of the mortar is reduced after the incorporation of self-healing agent, and the network structure formed by the hydration products is more dense. It can be seen from Fig. 7(c) and Fig. 7(d) that there are still unhydrated particles in the control group, and the hydrated products are distributed and dispersed. However, there are fewer unhydrated particles after the incorporation of self-healing agent. The connection is tighter. This also explains the improvement of the mechanical properties and impermeability of the mortar after mixing with bacterial.

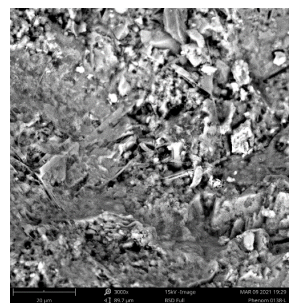

(a)

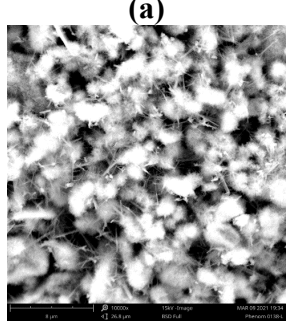

(c)

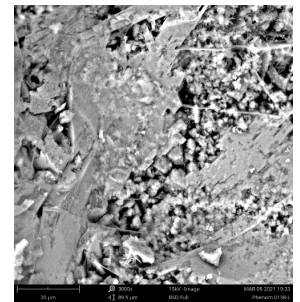

(b)

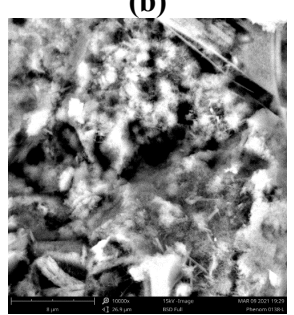

(d)
Fig. 7 Electronic micrographs of hardened cement mortars with (a) $0 \% \times 3000$; (b) $0 \% \times 10000$; (c) $2 \% \times 3000$; and (d) $2.0 \%$ $\times 10000$.

\section{Conclusion}

The purpose of the current work is to examine the effect of self-healing cement mortar. This investigation helps to understand the role of bacterial and the hardening characteristics of cement mortar. Considering the mechanical properties, shrinkage properties and impermeability, the following conclusions can be drawn:

(1) The mechanical properties increase with the increase of the water-cement ratio, but when the watercement ratio increases to 0.42 , the mechanical properties decrease with the increase of the water content, and the change trend of the $3 \mathrm{~d}$ and $7 \mathrm{~d}$ ages is the same. In addition, the addition of self-healing agent enhances the mechanical properties of cement mortar. This is because in the early stage, the hydration reaction of cement can be accelerated when the water-cement ratio is relatively large, but after the water-cement ratio continues to increase, the content of hydration products becomes smaller and the macro-mechanical properties become worse.

(2) The incorporation of fiber effectively enhances the toughness of cement mortar, maintains the crack width of the material, and creates favorable conditions for self-healing. However, the incorporation of fibers will weaken the compressive strength of cement mortar to a certain extent, so fibers can be appropriately incorporated into the corresponding materials.

(3) The self-healing agent will increase the selfshrinkage of cement materials, and the impermeability 
performance will increase with the increase of the amount of self-healing agent, but when the content reaches $1.5 \%$, the impermeability will decrease with the increase of the amount. In future studies, water reducing agents can be considered to improve mechanical properties and improve shrinkage characteristics.

\section{References}

1. De Muynck W, Cox K, De Belie N, Verstraete W. Bacterial carbonate precipitation as an alternative surface treatment for concrete. Constr Build Mater 2008; 22: 875-85.

2. Yang YG, Yang EH, Li VC. Autogenous healing of engineered cementitious composites at early age. Cem Concr Res 2011;41(2):176-83.

3. Q.Y. Cao, T.Y. Hao, B. Su, Crack self-healing properties of concrete withadhesive, Adv. Mater. Res. 2014,4:919-921.

4. M. Kayondo, R. Combrinck, W.P. Boshoff, State-ofthe-art review on plastic cracking of concrete, Construct. Build. Mater. 2019,225:886-899.

5. A. C. Ganesh, M. Muthukannan, R. Malathy, An Experimental Study on Effects of Bacterial Strain Combination in Fibre Concrete and Self-Healing Efficiency. KSCE Journal of Civil Engineering, 2019, 23(10): 4368-4377.

6. J. Qiu, H.S. Tan, E.H. Yang, Autogenous healing of early-age cracks in cementitious materials by superabsorbent polymers, Materials. 2020,13(3),60.

7. H.H. Nguyễn, J. Choi, K. Song, Self-healing properties of cement-based and alkali-activated slagbased fiber-reinforced composites, Construct. Build. Mater. 2018,165:801-811.

8. S.Gupta, H.W Kua, S.D Pang, Healing cement mortar by immobilization of bacteria in biochar: An integrated approach of self-healing and carbon sequestration, Cement Concr. Compos. 2018, 86: 238-254. 